\title{
Capabilities exchange through business interaction: An empirical investigation of a client-IT supplier relationship
}

\author{
Carlos Brito ${ }^{\mathrm{a}, *}$, Mafalda Nogueira ${ }^{\mathrm{b}}$ \\ ${ }^{a}$ Faculty of Economics, University of Porto, Rua Dr. Roberto Frias, 4200-464 Porto, Portugal \\ ${ }^{\mathrm{b}}$ Management School, University of Lancaster, Lancaster LA1-4YX, UK
}

\section{A R T I C L E I N F O}

\section{Article history:}

Received 9 June 2008

Received in revised form

16 April 2009

Accepted 4 May 2009

Keywords:

Interaction

Relationships

Information technologies

Capabilities

\begin{abstract}
A B S T R A C T
This article focuses on the opportunities for capabilities exchange within a specific business-to-business context: the relationship between a client and an information technology (IT) supplier. Research on the features of this type of relationship, although fairly extensive, has focused on IT implementation issues, relationship between IT resources, organisation performance and competitive advantage, IT outsourcing relationships and definition of IT capabilities. However, our understanding of the context where IT capabilities are exchanged within consultancy projects and how this exchange emerges is rather limited. The paper aims to bridge this gap by adopting the Industrial Marketing and Purchasing (IMP) group's interaction approach as a tool for conducting an in-depth investigation of a case study to analyse the context, the parties and the interactions through which IT capabilities are exchanged. The research reveals that interpersonal relationships between users and consultants within consultancy projects are crucial to establish a long-lasting and stable relationship. As a result, during consultancy projects IT-related resources, in the form of IT physical infrastructures, human IT resources and IT intangible resources are exchanged and combined to create or enhance IT capabilities. Furthermore, we also claim that the success of such an exchange depends very much on the degree of social and interpersonal exchange.
\end{abstract}

(c) 2009 Elsevier Ltd. All rights reserved.

\section{Introduction}

It is no longer a novelty that IT is changing the way companies perform. The importance of understanding the results of IT implementation is revealed by the amount of research dedicated to the subject. Lai and Mahapatra (1997) identified 71 papers related to IT implementation issues. Others adopting a resourcebased view (RBV) of the firm, focused on the relationship between IT resources, organisation performance and competitive advantage (Bharadwaj, 2000; Mata et al., 1995; Ross et al., 1996; Powell and Dent-Micallef, 1997; Tippins and Sohi, 2003) and on the definition of IT capabilities (Bharadwaj, 2000; Yongbeom et al., 2006; Duhan, 2007; Bharadwaj et al., 1999). IT outsourcing relationships are also being strongly discussed among researchers (Kern and Willcocks, 2002; Hurley, 2001; Gonzalez et al., 2006; Kishore et al., 2003; Goo et al., 2007; Lacity et al., 1996) where the reasons for success in IT adoption are shifted from the IT products implementation to the management of relationships with service providers (Kishore et al., 2003). The importance given to

\footnotetext{
* Corresponding author. Tel.: +351225 571100; fax: +351225505050

E-mail addresses: cbrito@fep.up.pt (C. Brito), m.nogueira@lancaster.ac.uk (M. Nogueira).
}

relationships in the context of IT implementation is also evident in research on client-consultant relationships (Mike, 2003; Shah, 1990; Chornoboy and Gardner, 1990; Larwood and Gattiker, 1986; Dawes et al., 2007). Despite these examples of IT research, existing literature relies more on what Bharadwaj (Bharadwaj et al., 1999) refers to as "anecdotal evidence, discussions with a few visionary IS executives or case studies of highly successful firms" (p. 379). This is particularly accurate when the subject on how to enhance IT capabilities is raised. The taxonomies of IT capabilities were identified (Bharadwaj, 2000; Duhan, 2007; Mulligan, 2002; Feeny and Willcocks, 1998), the importance of relationships with suppliers, consultants and service providers as keystones to successful implementations was also addressed (Kern and Willcocks, 2002; Goo et al., 2007; Mike, 2003; Webster, 1995; Lui and Chan, 2008; Zimmerman and Zelnio, 1986), but the links between IT capabilities development and relationships with IT suppliers were not fully explored. The researchers of the Industrial Marketing and Purchasing (IMP) group argue that capabilities are developed through interactions in the relationships with other parties (Håkansson and Snehota, 1989) and "if properly used supplier relationships can dramatically enhance the resources and capabilities that a company can use" (Ford et al., 2003, p. 97). In the same line, the capabilities perspective based on RBV suggests that relationships work as mechanisms to coordinate resources 
and capabilities that a company does not possess (Foss, 1999; Loasby, 1994, 1998).

In this sense, we have combined the contributions from the fields of industrial marketing and purchasing research and capabilities approach, specifically on IT capabilities, to argue that a company may boost their IT capabilities not only by purchasing and implementing IT resources but also through the process of interaction with the IT supplier during the implementation, which in turn will depend on the specific features of such a relationship. Therefore, this article seeks an understanding of the context, the parties and the interactions through which IT capabilities are exchanged within a client-IT supplier. To achieve this understanding, a single-case study was developed with two major goals: to define the key dimensions of the dyadic relationship between a company and an IT supplier and to explore the nature of IT capabilities as a type of exchange of the interaction process.

The paper is organised as follows. First, a review of the relevant literature is presented based on three main theoretical keystones: the IMP interaction model, the literature on consultancy relationships research and the IT capabilities approach. The section which follows presents the research propositions and explains the analytical framework. Thirdly, we address the research methodology undertaken to develop a single-case study, followed by the case analysis and discussion of the findings. The last section reveals the conclusions and implications of the study and brings in the limitations and suggestions for future research.

\section{Theoretical background}

\subsection{The IMP interaction approach}

A great amount of research on industrial markets have been conducted by academics within the Industrial Marketing and Purchasing group to provide a wider understanding of business markets in terms of dyadic buyer-supplier relationships and industrial networks in which those relationships are developed and managed (Axelsson and Easton, 1992; Ford, 1980; Ford, 2002; Ford et al., 1998; Håkansson, 1982, 1987; Håkansson and Snehota, 1995). The IMP group has provided a key conceptual model, often quoted in industrial markets studies, focused on the nature of buyer-supplier relationships-the interaction model (Håkansson, 1982). Originally developed in the $80 \mathrm{~s}$ in the context of manufacturing companies, the adoption of the model was later extended to explore relationships in services sectors. The model (Fig. 1) was adopted here to capture the key features of the client-IT supplier relationship since it provides a way of drawing the richness of relationships in a four-element analytical approach: the interacting parties, the interaction process, the interaction atmosphere and the interaction environment (Håkansson, 1982).

This approach takes relationships as a process of continuous exchanges (products and services, information, social and financial exchanges) developed in short-term episodes. Such exchange episodes may become institutionalized over time leading to expectations for further exchanges and for long-term relationships. In addition, the parties may make adaptations in the elements exchanged or in the process of exchange which includes adaptations of the product specification, product design, manufacturing processes, planning, delivery procedures, stockholding, administrative procedures or financial procedures (Håkansson, 1982). The interaction process also depends on the idiosyncrasies of the participants, organisations or individuals. Organisations are characterized in terms of technology, size, structure, strategy and experience, whereas individuals are characterized by their functional area, hierarchical level, personality, experience and motivation. The environment within which interaction takes place is characterized in terms of market structure, dynamism, internationalization, position in the manufacturing channel and social system. Finally, the atmosphere affecting and being affected by the interaction is described in terms of power-dependence relationships, conflict or cooperation, closeness and distance and mutual expectations.

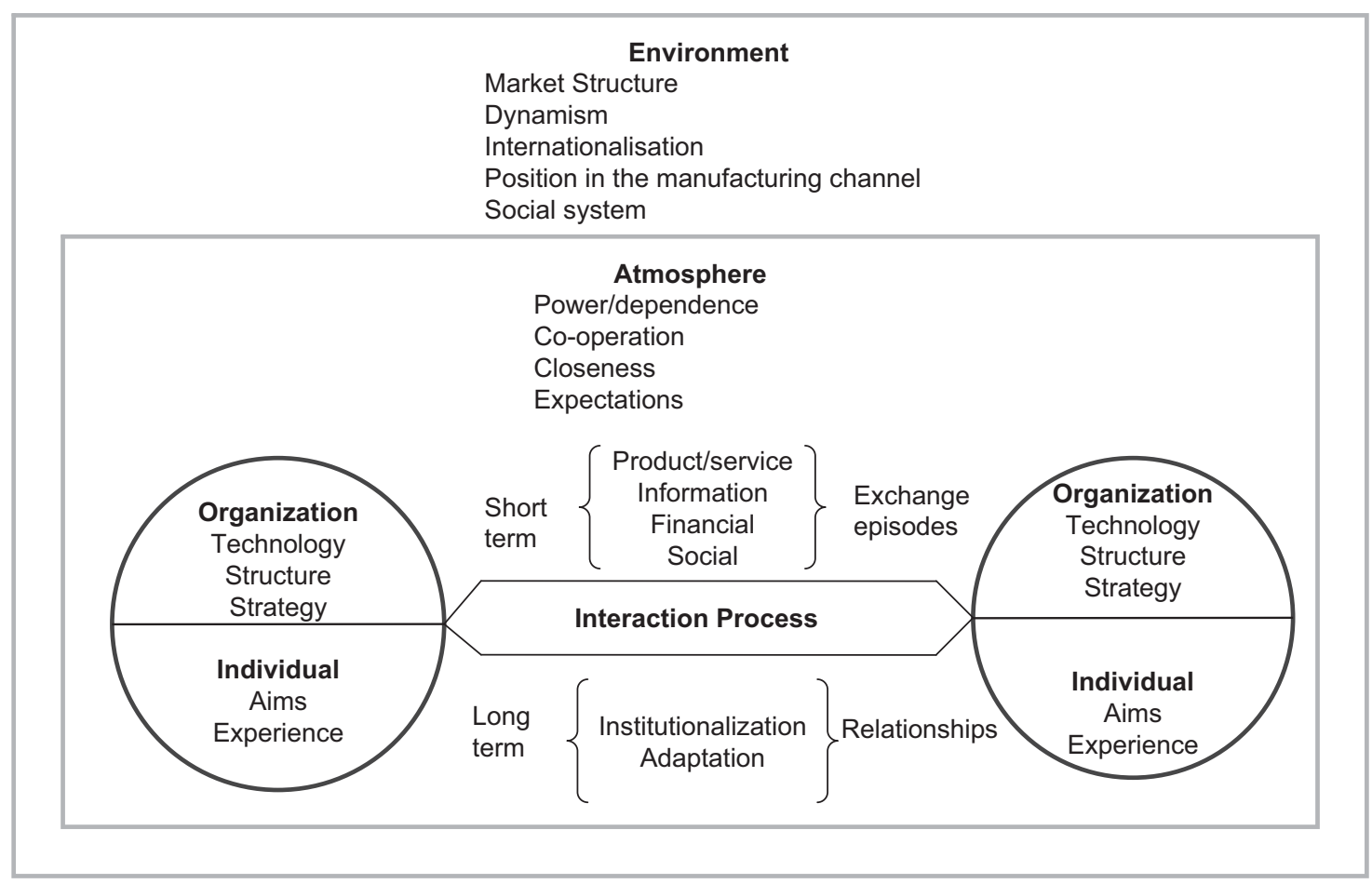

Fig. 1. The IMP Interaction Model (Håkansson, 1982, p. 21). 
As shown by some researchers from the IMP group, the interaction approach is particularly suitable to investigate dyadic relationships in IT context (Leek et al., 2003; Naudé et al., 2000). Information Systems researchers also adopted this model to explore outsourcing relationships (Kern and Willcocks, 2002) claiming that it helps researchers to "catch some fundamental aspects of interorganisational relationships in IT outsourcing" (p.12). Thus, the adoption of the interaction model to investigate a client-IT supplier relationship seems worthwhile in the context of our research objectives.

\subsection{Client-IT supplier relationships}

There are a vast range of studies on client-IT supplier relationships: client-consultant relationships (Mike, 2003; Shah, 1990; Chornoboy and Gardner, 1990; Larwood and Gattiker, 1986; Dawes et al., 2007), IT outsourcing relationships (Kern and Willcocks, 2002; Hurley, 2001; Gonzalez et al., 2006; Kishore et al., 2003; Goo et al., 2007; Lacity et al., 1996) and client-IT supplier/IT service provider relationships (Kishore et al., 2003). These studies emphasize the importance of relationship management and partnerships with suppliers to achieve benefits from IT adoption. Karantinou and Hogg (1999), for example, described the features of client-consultant relationships combining IMP contributions and relationship marketing approach. Complexity, information asymmetry, conflicts of interests and differences in perceptions and expectations between clients and consultants are some of the identified features. In consultancy projects, clients are seeking for both human capital (in the form of new skills and knowledge), and structural capital (in the form of knowledge bases and best practices, due to the expertise consultancy firms can offer) (Willcocks et al., 2004). Therefore, skills and knowledge achieved in consultancy projects may be resources that work together to create IT capabilities. Surprisingly, none of those studies considered IT capabilities exchange as a potential feature of a client-IT supplier relationship which endorsed the motivation to conduct this investigation.

Another feature of this type of relationship is the organisational form through which exchanges are developed-the consultancy projects (Niewiem and Richter, 2004). The literature on project marketing provides some valuable insights that cannot be neglected. The discontinuity trend, as a consequence of the time breaks generally observed between projects must be considered if one seeks an understanding of client-consultant relationships. The capacity to manage such a relationship is limited by the fact that "the purchasing of a project by a given client may not be repeated until a few years have elapsed since the previous purchase" (Cova and Salle, 2000, p. 670). The adoption of the interaction model (Håkansson, 1982) to understand social exchanges in IT outsourcing was described elsewhere (Kern and Willcocks, 2002), but the role they play in struggling with discontinuity between projects was not addressed.

Studies on client-consultant dyads (Niewiem and Richter, 2004; Graubner and Richter, 2003) suggest that such relationships are observing fundamental changes in the last decade since "consulting market is turning from a sellers' into a buyers' market" (Niewiem and Richter, 2004, p. 9). Evidence shows that consultancies can no longer obtain large margins as in the past. Competition is growing fast and clients are becoming more and more knowledgeable and demanding (Graubner and Richter, 2003), especially after the scandals involving well-known consultancy firms namely Enron, Arthur-Anderson or KPMG. Interaction between firms is therefore crucial to reinforce the strength of the relationship and personal interaction is cited as the "most important sources of actionable and hence relevant knowledge" in client-consultant relationships" (p. 12) where both parties can learn and benefit from each other. A parallel may be established with findings from a study on the determinants of enterprise resource planning (ERP) implementation knowledge transfer (Xu and Ma, 2008) according to which the benefits of ERP depend on knowledge and skills transfer within a bidirectional flow from consultants to users and vice versa. In line with this argument, we see knowledge/skills in IT implementation context as potential drivers to enhance IT capabilities in both parties of the relationship. The exchange of knowledge and skills are therefore highlighted in the literature as a feature of such relationships (Niewiem and Richter, 2004), which lead us to question how this exchange emerges in consultancy projects. Understanding how this transference or exchange occurs is therefore crucial to take the best out of the IT-based relationships.

\subsection{IT capabilities approach}

IT is being claimed as a source of competitive advantage and recognised as an organisational capability (Mata et al., 1995; Ross et al., 1996; Feeny and Willcocks, 1998; Clemons and Row, 1991). The IT capability literature is rooted in the RBV, which highlights the link between competitive advantage and resources of the firm, seen as firm-specific, rare and difficult to be imitated by the competitors (Barney, 1991; Foss and Roberston, 2000). This paper endorses much of the spirit of the RBV but does not seek to engage in this particular debate. Rather the aim is to step forward and suggest a framework within which IT capabilities are leveraged in client-IT supplier relationships. In this sense our focus is directed to what is being defined as IT capabilities. In the context of IT resources, it is generally argued that various IT-related resources may be combined to form an IT capability that is valuable, rare, non-imitable and non-substitutable (Mata et al., 1995). It can be seen as the "organisation's ability to understand and utilize IT tools and processes that are needed to manage market and customer information" (Tippins and Sohi, 2003, p. 748) which comprises IT objects, IT knowledge and IT operations. In line with Bharadwaj's (2000) definition of IT capability, we understand this ability "as the ability to mobilize and deploy IT-based resources in combination or co-presence with other resources and capabilities" (p. 171). Over the past two decades, researchers have been studying what type of IT resources may be considered as sources of competitive advantage and combined to create IT capabilities: 1) IT physical infrastructures, namely, shared platforms and databases (Ross et al., 1996), computer-based hardware and software (Bharadwaj, 2000; Tippins and Sohi, 2003); 2) technical and managerial skills of human resources (Bharadwaj, 2000; Mata et al., 1995; Ross et al., 1996; Tippins and Sohi, 2003), 3) relationship assets in the sense of coordination and interaction with user community (Mata et al., 1995; Ross et al., 1996), 4) capabilities to acquire technologies (Flowers, 2007) and 5) IT-enabled intangibles such as synergies, customer orientation and knowledge assets (Bharadwaj, 2000) are some of the relevant resources that work together to create IT capabilities referred in the literature.

Bharadwaj's taxonomy (Bharadwaj, 2000) was adopted to conduct the empirical investigation as it presents a comprehensive analysis of IT capabilities. He suggests a scheme to classify IT resources capable of creating organisational capabilities: i) IT physical infrastructure, ii) IT human resources comprising managerial and technical skills and iii) IT intangible resources where knowledge assets, customer orientation and synergies are included. IT physical infrastructure comprises computer and communication technologies and shared technical platforms and databases, which in turn are essential to systems integration 
and to develop cost-effective IT applications. Human IT resources cover the technical IT skills (e.g. programming, systems analysis and design and competencies in emerging technologies) and managerial skills, often tacit and dependent on interpersonal relationships, such as leadership, project management skills, coordination and interaction with users. Lastly, IT-enabled intangibles embrace the intangible benefits derived from IT utilization. The way users employ technology is regarded as a knowledge that is tacit, idiosyncratic and deeply embedded on the organisation. Firstly, IT is an indispensable ingredient for achieving high levels of customer orientation, which enables firms to track and predict shifts in customer choices, to forecast product demand and to improve customer service. Secondly, "a key aspect of a firm's intangible resources is its intellectual capital or knowledge assets" (p. 175). IT systems embedded with employees' knowledge enable the development of new knowledge and crystallization of existing knowledge, which leverages the firm's ability to respond to environmental changes. Lastly, IT also promotes synergies through sharing of knowledge and information across all business units, which enables firms to be more flexible and to respond faster to market needs. The competitive advantages associated with synergies are, therefore, difficult to imitate because they are "often achieved under a unique set of circumstances and on the basis of firm-specific resources" (p. 176).

\section{Research questions and analytical framework}

This research aims at exploring the opportunities for IT capabilities exchange within the relationship between a client and an IT supplier. From the literature review on the topic, an avenue for research was identified since existing studies focus on the adoption of IT resources to enhance organisation performance and competitive advantage, the identification of IT capabilities, IT outsourcing and client-consultant relationship's management. However, the understanding about the context where IT capabilities are exchanged within consultancy projects and how this exchange emerges is rather scarce.

The research questions were thus formulated as follows. First, we aim to expand our understanding of the characteristics of client-IT supplier relationships. Some of their specificities were revealed in the theoretical background section; however, we concluded from the revision of the relevant literature that understanding such characteristics in a dynamic context of interaction was scarcely approached. Therefore, the first research question is:

What are the features of the interaction process within a client-IT supplier relationship?

Secondly, the literature on the topic is mainly focused on IT implementation issues, relationship between IT resources, organisation performance and competitive advantage, IT outsourcing relationships and definition of IT capabilities. What is missing is an understanding on how IT capabilities are leveraged in client-IT supplier relationships beyond the mere implementation of IT products. Therefore the second research question was formulated as follows:

How can a company enhance their capabilities through interactions with IT suppliers within consultancy projects?

We seek to address these research questions by adopting the interaction model (Håkansson, 1982) as a tool to analyse the

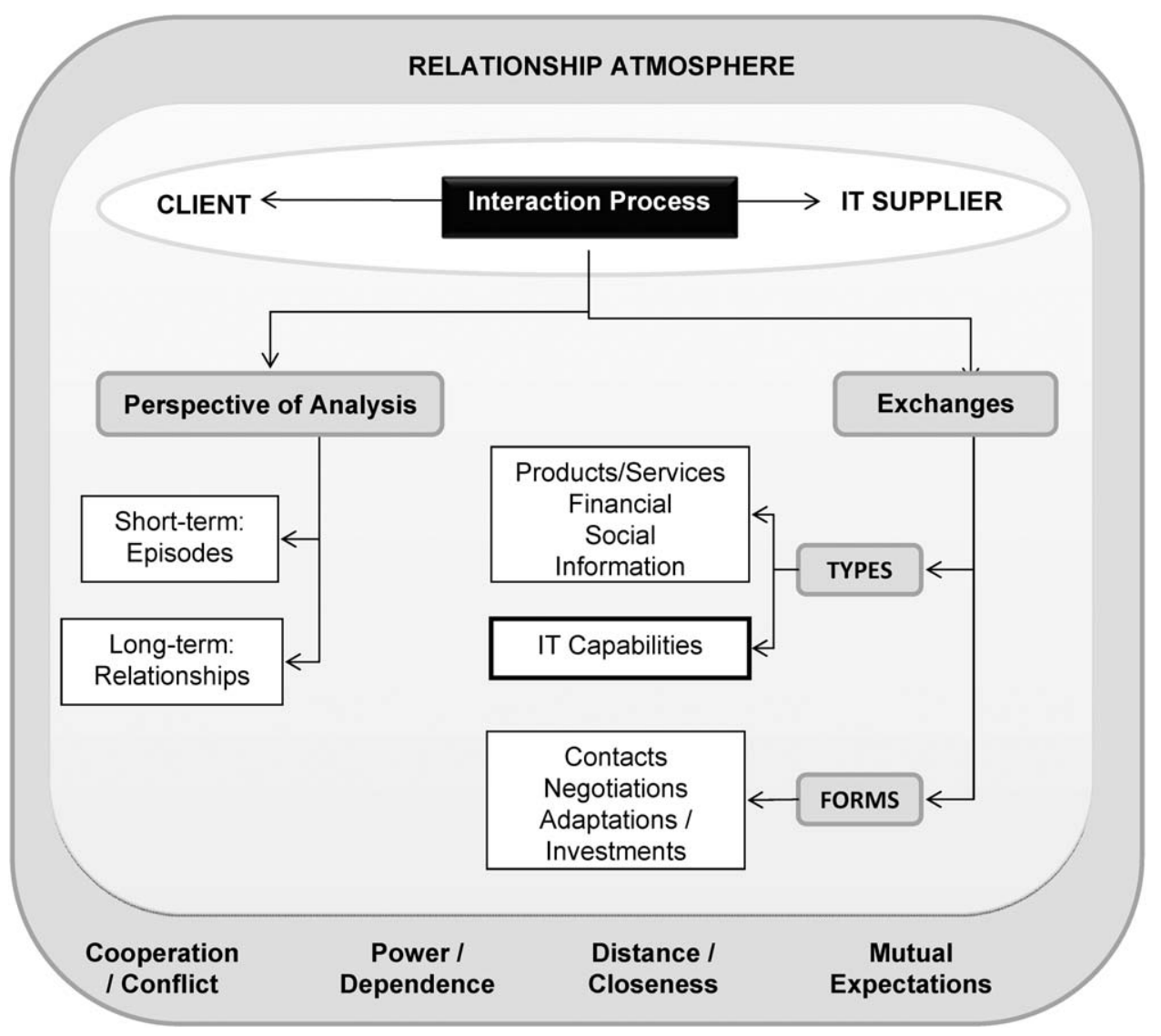

Fig. 2. Analytical framework. 
context, the parties and the interactions through which IT capabilities are exchanged. In this sense, an analytical framework (Fig. 2) was constructed on the basis of: 1) the IMP work on the understanding of business-to-business relationships and interactions (e.g. Ford, 1980, 2002; Håkansson, 1982; Ford et al., 1986; Håkansson and Ford, 2002; Håkansson and Prenkert, 2004) and 2) the approach of IT as capabilities of the firm (e.g. Bharadwaj, 2000; Mata et al., 1995; Ross et al., 1996; Rockart et al., 1996).

The framework embodies the dyadic relationship between a client and an IT supplier by exploring the dimensions of the original interaction process (Håkansson, 1982) and by adding a new type of exchange - IT capabilities - proposed here as a critical dimension to characterize this specific kind of relationship. Firstly, inspired by the original model (Håkansson, 1982) the interaction process is reflected as embedded by its atmosphere and explored in two perspectives of analysis. The short-term episodes may reflect transactions, negotiations, consultancy projects, etc. whereas the long-term perspective intends to represent the evolution of the relationship. Each episode involves different types of exchanges, namely, products and services, social and financial exchange and information. In addition, these exchange types are a result of contacts and negotiations developed between the parties as well as necessary investments and adaptations through which the relationship is institutionalized. In a client-IT supplier relationship context the latter may include, for example, adaptations in software, working processes, planning, delivery procedures, stockholding, administrative procedures, etc. Finally, the atmosphere affecting and being affected by the interaction is described in terms of cooperation or conflict positions during IT projects, contract negotiations; power-dependence positions in the dyad, distance and closeness between parties and mutual expectations about the past, present and future of the relationship (Håkansson, 1982). Secondly, the IT capabilities access is introduced as a specific type of exchange that emerges throughout the interaction episodes. Adopting a capabilities approach, this paper

Table 1

Analytical dimensions.

\begin{tabular}{|c|c|c|c|}
\hline Dimensions & Sub-dimensions & & \\
\hline \multirow[t]{5}{*}{ A } & \multirow[t]{5}{*}{$\begin{array}{l}\text { Interaction } \\
\text { process }\end{array}$} & A1 & $\begin{array}{l}\text { Key actors } \\
\text { Companies' history and focal activities } \\
\text { Market positions }\end{array}$ \\
\hline & & A2 & $\begin{array}{l}\text { Relationship background } \\
\text { Relationship "age" and history } \\
\text { Motivations for supplier selection }\end{array}$ \\
\hline & & A3 & $\begin{array}{l}\text { Perspectives of analysis } \\
\text { Short term: episodes } \\
\text { Long term: relationship evolution }\end{array}$ \\
\hline & & A4 & $\begin{array}{l}\text { Exchanges (IMP view) } \\
\text { Types: product/service, information, } \\
\text { social, financial } \\
\text { Forms: contacts, negotiations, } \\
\text { adaptations/investments }\end{array}$ \\
\hline & & A5 & $\begin{array}{l}\text { Relationship atmosphere } \\
\text { Cooperation and conflict } \\
\text { Power and dependence } \\
\text { Distance and closeness } \\
\text { Mutual expectations }\end{array}$ \\
\hline \multirow[t]{3}{*}{ B } & \multirow[t]{3}{*}{$\begin{array}{l}\text { IT capabilities } \\
\text { exchange }\end{array}$} & B1 & $\begin{array}{l}\text { Tangible } \\
\text { Physical infra-structures }\end{array}$ \\
\hline & & B2 & $\begin{array}{l}\text { Human IT resources } \\
\text { Technical and managerial skills }\end{array}$ \\
\hline & & B3 & $\begin{array}{l}\text { Intangible } \\
\text { Customer orientation } \\
\text { Synergies } \\
\text { Knowledge assets or intellectual capital }\end{array}$ \\
\hline
\end{tabular}

endorses a wide range of researchers who look into inter-firm relationships as a key mechanism to coordinate capabilities (Loasby, 1994; Foss and Roberston, 2000; Foss and Loasby, 1998; Mota and de Castro, 2005). Therefore, considering IT as capabilities of the firm (Bharadwaj, 2000; Mata et al., 1995), the framework suggests that access to new IT capabilities may emerge from consultancy projects during succeeding interaction episodes.

The framework was designed with two major concerns: on one hand, to fairly represent the overall interaction process between the parties, comprising the opportunities to access IT capabilities as a type of exchange; on the other hand, to be used as a tool to conduct the empirical investigation in the sense that each dimension of the framework was operated as bedrock to collect, organise and analyse the empirical data (Table 1 ).

\section{Methodology}

Research methodology: It is argued that case research may provide a huge contribution to the development of theory in purchasing and supply management fields (Dubois and Araujo, 2007). Time delimitation, definition of boundaries and dynamic nature of relationships embedded in networks are said to be problematic issues, which can be properly tackled with case studies as case methods are concerned with dynamics and changes over time and are able to provide longitudinal data (Dubois and Araujo, 2007, 2004; Dubois and Gadde, 2002; Easton, 1998). This research deals with business interactions between actors within which a specific type of capabilities may be exchanged. Therefore, given the nature of the research problem and the type of research questions, the adoption of case research seems appropriate to conduct this investigation. A reflection on what type of case would be more suitable in the context of our research aims led us to search for a dyadic relationship between a client and an IT supplier who was simultaneously an IT physical infrastructure supplier, a service provider in terms of technical and managerial skills and a business consultant. Having those three features together would provide a rich context within which different IT capabilities could be exchanged. Furthermore, it would also have to involve a long relationship involving numerous and complex IT projects in order to grant a plentiful collection of inspirational interaction episodes. The relevance of the selected case is thus associated with the extensive supplier offer in terms of IT-related products and services and the length of the relationship comprising different and numerous projects.

Sampling: Adopting the IMP interaction model as a keystone to design the analytical framework, a single-case design with embedded cases was carried out. The dyadic relationship was at the heart of the study whereas the interaction episodes were the embedded cases providing the means to delimit time borders and define research boundaries. An in-depth analysis of a relationship between a client and an IT supplier was undertaken and 18 interaction episodes based on IT implementation projects (Enterprise Resource Planning-ERP, Customer Relationship Management-CRM and Domino software for electronic e-mail and workflow processes), contract negotiations, search for new solutions, etc., which occurred between 1980 and 2006, were comprehensively investigated (see Appendix A). The companies involved in the selected focal relationship were a paint manufacturer and their main IT supplier. The supplier company was selected based on a privileged access rationale. The selection of the client was attached to two main reasons: firstly, it is the Iberia market leader of paint industry and one of the most technology-oriented companies in Portugal and secondly, because 
it holds a key position in the supplier's customer portfolio, which implies the involvement of both parties in numerous consultancy projects.

Data collection: The importance of data triangulation to guarantee validity and reliability in case research, especially in single-case designs, has been widely recognised by a number of authors (Dubois and Gadde, 2002; Bonoma, 1985; Johnston et al., 1999; Yin, 1994). Although, this paper does not seek to generalize findings, but to provide new insights on the understanding of business relationships as drivers to exchange capabilities, a considerable amount of data was sought and obtained in order to investigate the research problem. As claimed by Easton (1998), a set of multiple data sources on both sides of the dyad is needed to fully understand the relationship complexity. As a result, multiple data sources were investigated and crossed to corroborate findings. Firstly, the research was based on semi-structured interviews conducted in both companies, where the framework's dimensions and sub-dimensions (see Table 1) were investigated. Fourteen interviews were carried out with people who were highly involved in the IT implementation episodes throughout the period 1980-2006. From the supplier side, project managers, key account manager, product manager and business and technical consultants were interviewed. From the client side, the IT department director, project managers and six final users were questioned. All the interviews were recorded and fully transcribed. Secondly, a wide range of documents was analysed from both sides of the dyad. In one hand, rich information was collected from the institutional websites where the researchers had access to companies' annual reports, market positions, histories, missions and focal activities. Newspaper articles and newsletters from both companies were also used to build the case study. On the other hand, a large amount of internal documentation was provided by both firms, which played an important role to corroborate the insights given by the interviewees (minutes from IT projects meetings related to different episodes, reports related to evaluation of IT needs, analysis of software adaptations, project management,; commercial proposals, contracts and power point presentations used by the supplier to present new solutions). Finally, observation was also a rich source of data. Observationparticipation was possible since one of the researchers was involved in one of the IT projects, which provided the opportunity to get close access to final users and observe their expectations and feelings about the relationship with the IT supplier.

Data analysis: In a first stage, the multiple sources of empirical evidence were organised and displayed in a set of tables. Each table was related to each dimension of the analytical framework (following Table 1).Within a table, each column represented a sub-dimension of the model and the $n$ lines represented all the references retrieved from different sources related to that dimension. This way, the findings from each dimension were triangulated and corroborated by different sources of evidence, which provided a rich basis to build the case. In a second stage, the analysis of the tables gave place to a unique report describing the case.

\section{Case analysis}

As described in Section 3, the analytical framework was designed not only to reflect the potential IT capabilities exchange and the overall interaction process between the parties but also to provide a useful tool to conduct the empirical investigation. In this sense, the case analysis is developed according to the elements of the framework and sub-divided along two major dimensions following Table 1: the interaction process and the IT capabilities exchange.

\subsection{Dimension A: the interaction process}

\subsubsection{Key actors}

The companies involved in the focal relationship were the client PaintCo and the supplier ITSup ${ }^{1}$. PaintCo is the largest Portuguese paint group and the only one in their market quoted on the stock exchange. With products divided into decorative, industrial, car repainting, anticorrosive and accessories segments, the group has around 800 employees and comprises several companies with nearly 70 wholly-owned stores and factories in Portugal, Spain, Angola, Mozambique and Cape Verde. Ranked 16th in Europe and 46th worldwide, PaintCo is the Iberian leader in the paint market. ITSup, in turn, is a leading provider of business systems, with a presence on the Stockholm stock exchange. Its offer includes business applications and professional services extended to several areas (e.g. sales and marketing support, customer relationship management, supply chain management, manufacturing and distribution, financial control and business intelligence). Portugal is the headquarters for the Iberian competences centre and a founder of the Southern Area of ITSup Group, along with Spain, Italy, France, Brazil and Colombia.

\subsubsection{Relationship background}

The relationship between PaintCo and ITSup started in the 1980s, not as a standard client-supplier relationship, but as a partnership to develop software. At the time, the client was totally autonomous in developing in-house IT. Through personal relationships between top managers, PaintCo and ITSup decided to jointly develop a financial solution suitable for the requirements of the painting industry. Afterwards small IT projects (see Appendix A) strengthened the relationship. In the early 2000s, observing a fast growth, PaintCo decided to adopt a corporate philosophy. The main goal was to standardise working procedures and define a new business model used universally by the group. The new strategy brought with it the need to search for an Enterprise Resource Planning system. ITSup was first short-listed as a potential supplier and then selected, largely due to the relationship of trust that had already existed for nearly twenty years. The ERP covered the financial, commercial and distribution areas. Other departments, such as R\&D and human resources had specific software adapted to their requirements, which led to a massive need to create interfaces between different systems. Currently, PaintCo maintains frequent contact with ITSup.

\subsubsection{Perspectives of analysis}

In a short-term perspective, episodes comprised mainly negotiations and consultancy projects and became intense from the moment PaintCo decided to invest in ITSup's ERP solution. The ERP project turned out to be the most conspicuous of the relationship and considered the point of departure for subsequent projects. The following projects consisted of programming language acquisitions, adaptations to existing software, physical infrastructure renewal, Customer Relationship Management system among others.

It is this relationship between people from both organisations that helps maintaining a normal relationship. It sometimes involved all the other projects that go beyond the ERP and we end up giving [ITSup] priority for supplying. (PaintCo, IT manager)

In a long-term perspective, the several episodes following the initial partnership established in the late 1980s, gave place to a

\footnotetext{
${ }^{1}$ For confidentiality reasons, companies' names are fictional
} 
strong and solid relationship, seriously energised through personal and social relationships amongst personnel from both companies. In fact, personal and social relationships were identified as a central characteristic of client-IT supplier relationships, frequently being mentioned in the interviews:

The relationship between people evolved over time. At the beginning, there were some difficult moments with some of those people, but these were moments that led to the creation of credibility and confidence that characterised the relationship from that moment onwards. There is a mutual respect, one that was difficult to conquer but that ended up being achieved and that was the origin of many positive outcomes. (ITSup, key account manager)

\subsubsection{Exchanges}

Exchange types: Throughout several episodes that were considered in the analysis, the following exchange types were identified: products and services (hardware, software and consultancy professional services), financial exchange (disbursements), information exchange (about work procedures and routines and activity sectors) and social exchange. Social exchange had on one hand and during the projects, a daily, intense and informal nature contributing to the development of personal bonding between the people from both parties. On the other hand, in discontinuity periods between projects, social exchange played the role of a communication bridge, which explains how the relationship could carry on, healthy and stable, for twenty years even witnessing several and extensive hiatus between projects.

Exchange forms: The exchanges took several forms. Specific negotiations occurred for each project and were formalised via contracts. There were also intense and frequent formal and informal contacts via diverse channels, namely project meetings, support documentation, daily encounters, e-mail, phone and fax. Finally, and what was more obvious, was that both organisations made huge adaptations and investments. Both carried out high time and human resources investments so that the project's success would not be jeopardised. In terms of adaptations, we highlight the client adaptations to new working processes and uncountable supplier adaptations to standard software in order to be able to reply to client's demands. This was evident in some statements given by the interviewees, for example:

A significant number of specific programs were developed... and despite the huge investment in services of additional programming that it involved, we were the ones that had to adapt to [PaintCo]'s processes. (ITSup, consultant)

\subsubsection{Relationship atmosphere}

Power/dependence: The client seems to hold a greater control over the relationship, apparently because of strategic reference in the client portfolio of the supplier as well as a considerable source of income. The supplier expects the client, as Iberian leader in sales volume and innovation, to play a key role of opinion maker in the diffusion of positive experience of the relationship. The power position held by the client became clear as all their solicitations and requirements for adaptations to software were always approved by ITSup. As stated by an interviewee from the supply side:

...We are giving up on our role and becoming someone that does everything that the client wants us to and by doing this we are reducing our value, renouncing our own experience (...). This was a lesson I learned with this project: sometimes it is necessary to be able to say no to the client. (ITSup, IT product manager)
This evidence was corroborated by documents describing the amount of adaptations to the standard software that were accepted and developed by the supplier. Despite this control position, the client seems to maintain a certain level of dependence toward the supplier, as a consequence of frequently having the need to expand IT exploitation, eliminate program errors and demand for changes in standard programs.

Conflict/cooperation: The relationship atmosphere was not dominated by conflict although there were some conflict situations, mainly due to the high number of software adaptations and following delays in the accomplishment of pre-defined implementation deadlines. Still, both parties agreed there was strong cooperation between them in order to solve the conflicts.

The project is above all about empathy, relationships and about transmitting an attitude of partnership and cooperation. Being partners is very important and it means that we are able to sometimes behave as PaintCo employees and the other way around. We interact and change positions with the aim of solving problems that arise now and then. (ITSup, key account manager)

This cooperation included the implementation of measures by the project management team, mostly at the level of a reinforcement of the involvement of PaintCo's users in the prompt identification of non-conformities and consequent need to change standard programs and at the level of postponement of implementation deadlines. In fact, the majority of the interviewees emphasized the importance of cooperation between project leaders from both sides as a key dimension for a good relationship:

At the beginning, we both went through some difficulties, but as far as we can see, it all got sorted out quite peacefully... there weren't any conflicts, just the normal problems associated with the ERP implementation and that got solved through the privileged contact that exists between PaintCo and ITSup top managers. This privileged contact allows balancing a relationship that is considered much closer than any other by which some other supplier would come in to the company, implement the solution and then forget about it. (PaintCo, ERP project manager)

Closeness/distance: Although the projects were formalised by contracts, the decisive role of personal and social bonds for increase in proximity between parties was highlighted. On the relationship's distance in its several dimensions (cultural, social, technological, temporal and geographic), only the temporal distance might have some relevant meaning, given the length of the projects, especially the ERP project.

Mutual expectations: Both companies showed common expectations on relationship continuity, as well as in the costs and benefits associated with the relationship.

\subsection{Dimension B: IT capabilities exchange}

\subsubsection{IT tangible capabilities}

The relationship allowed the client to access IT tangible capabilities, which previously did not possess. The ERP project demanded a new physical infrastructure (information systems, interfaces between systems, hardware) common to all companies of the group. In this sense, these physical resources provided the client with a universal platform of information sharing and distribution. From this project onwards, it was possible to implement standardized working processes, allowing the client to take advantage of synergies generation between several units. The 
acquisition of software for application development (Lotus Notes software), another IT physical resource, also granted PaintCo with a greater autonomy to develop new applications in-house and to proceed to changes of existing software.

"From Lotus on it was possible to go beyond ERP areas. It allows us to advance to Quality Management, Environmental Management, Safety and Hygiene, Documental Management." (PaintCo, CRM project manager)

\subsubsection{IT human resources}

PaintCo users increased their technical skills on programming techniques and systems administration, through observation in daily, intense and informal contacts with ITSup consultants. As stated by an interviewee from the client side:

[ITSup] certified consultants managed to transport their knowledge to us and helped us immensely. My competences augmented, undoubtedly, throughout Lotus Notes implementation. (PaintCo, CRM project manager)

Interestingly is that the supplier acquired greater capabilities in the use of its own software by providing training, simultaneously, to placement consultants and PaintCo users throughout the ERP project. Nowadays, some of those apprentices are key consultants of ITSup. As stated by one interviewee from the client side "ITSup won a lot more with our projects than we did, in terms of acquired knowledge." From the several projects, ITSup was also able to increase their own capabilities in the best practices for the paint sector. Furthermore, both companies acquired new knowledge on project management practice which was considered by the supplier as a major element of added value retrieved mainly from the ERP project.

Today, we both acquired capabilities that allow us going in to any other project of the same dimension (...). I didn't get those capabilities with project management courses; I got them with PaintCo in a remarkable experience for all people that took part in the project. (ITSup, ERP project manager)

In fact, the frequent (but expected) conflicting situations that emerged from the high number of software adaptations and implementation delays along with PaintCo's power position, can explain this statement. Both events pressured the supplier to develop and deepen new skills in project management in order to fulfil PaintCo's expectations.

\subsubsection{IT intangible capabilities}

Several episodes of the relationship contributed to PaintCo's access to intangible IT capabilities in the form of Bharadwaj's concept of intellectual capital. Once again the informal relationships between PaintCo's users and ITSup's consultants brought out the conditions to build new knowledge in several areas: about PaintCo's processes, about the chaining activities between departments and also about the IT that supported the development of those processes and activities as a whole, and not as atomistic processes and activities supported by independent IT systems. Taking advantage of synergies was also possible after the infrastructure implementation. A group knowledge that exceeds the knowledge held by individuals and companies was generated, especially from the ERP episode, where a central database/server stored and unified all the informations about customers, products and processes retrieved from all companies to be afterwards shared by the whole group.

One of the major aims of the project was the creation of a 'corporate' model that would guarantee that when a new customer registration took place in one company of the group, this registration would be diffused by all remaining companies so that all could know the customer in the same way (...) This notion is today implemented throughout the four main areas financial, sales and logistics, manufacturing, and research \& development - and throughout every company of the group, either Portuguese or Spanish. (ITSup, IT manager)

There were also some synergies resulting from that knowledge they promoted, and consequently a greater customer orientation in the sense of providing a better service.

Now I'm able to know exactly which products are being supplied to each customer, and this allows me putting into action specific campaigns for products with inferior rotativity and I can adjust my offer for each customer in a specific way. (PaintCo, final user 1)

In sum, the analysis of the case provided valuable findings to address the purpose of our research. The next section elaborates on the key dimensions of a client-IT supplier relationship and on the opportunities to exchange IT capabilities.

\section{Discussion}

The case provides relevant findings about the features of a business relationship based on the transaction of IT-related products and services. One of the distinctive features of such a relationship is the critical role played by social exchanges as illustrated by the case of ITSup and PaintCo. In fact, our proposition that IT capabilities may be exchanged within interactions in a dyad should be rephrased in the sense that social exchanges are important keystones, if not the most important, to allow IT capabilities exchange to occur. The potential value of the suggested analytical framework and findings will be discussed in detail in the following sections.

\subsection{About the features of the interaction between client and IT supplier}

The interaction approach proved to be highly stimulating as a tool to capture the fundamental dimensions of a client-IT supplier as demonstrated previously by other researchers as Kern and Willcocks (2002) or Leek et al. (2003). Firstly, about the actors, our findings revealed the importance of having in-depth knowledge about the parties in interaction to fully understand the evolution of the relationship as suggested by Håkansson (1982) in the original model. Both parties in this study are large companies in terms of size and market positions, but more importantly they are technology-oriented which provided the means to develop a technological partnership in $80 \mathrm{~s}$. A balance between IT skills and knowledge possession may have triggered the beginning of a 20-year relationship during which each company enhanced their IT resources to create new or improve existing IT capabilities.

Secondly, about the short-term and long-term perspectives, our findings reinforce the view that a relationship between a client and a consultant is generally organised within time-framed consultancy projects, as suggested by Niewiem and Richter (2004). Following the IMP view (Håkansson, 1982), we see consultancy projects as processes of continuous exchanges, which can become institutionalized over time leading to expectations to further exchanges and to long-term relationships. Relationships that deal with complex IT implementation (such as an ERP or CRM system) are normally organised under a project umbrella where each project emerges and is managed based on previous 
experience with the supplier. This suggestion goes in line with the view of Håkansson et al. (1999) according to whom in industrial contexts, companies tend to get involved in new projects with suppliers who provided positive experiences in the past.

Thirdly, about the types of exchanges, we also highlight as demonstrated elsewhere (Kern and Willcocks, 2002) the importance of social exchanges to sustain the relationship. Citing Kern's work in the past, Kern and Wilcocks (2002) claimed that "social exchanges are possible the most underrated and ignored dimension by researchers who have looked at the outsourcing relationships" (p. 14). Therefore they attempted to fill this gap by suggesting that social exchanges are a guarantee of the relationship continuity, especially in situations of disputes and conflicts. Our findings revealed similar conclusions but moreover highlighted a new role. As emphasized in the theoretical background section, relationships organised in consultancy projects tend to 'suffer' from a discontinuity trend between projects (Cova and Salle, 2000). Our analysis provided peremptory answers from interviewees about the importance of social exchanges to fill the temporal gap between projects and even to discuss new projects in between. Fourthly, about the forms of exchanges, it was clear that the magnitude of adaptations and investments undertaken in PaintCo-ITSup case led to further projects and further involvements between them. In complex IT-based projects these adaptations were said to be highly influential in manipulating powerdependence positions held by the parties.

Lastly, about the interaction atmosphere within a client-IT supplier relationship, we agree with previous research (Kern and Willcocks, 2002; Karantinou and Hogg, 2001) on the consideration of conflict, commitment, power and dependency as behavioural dimensions of the relationship. However our findings on the power and control positions support a reversed view of traditional perspectives on IT outsourcing relationships. Kern and Wilcocks (2002) argued that "traditionally, clients expect that the supplier takes over and delivers the service while the client stands back and monitors" (p. 16). They claimed this is a misperception, because $70 \%$ of the clients' time is spent in managing the relationship. We concur with this view but we further argue that instead of standing back, monitoring or managing the relationship, the client has the power to control the relationship, if holds a key position in the supplier's customer portfolio.

\subsection{About the opportunities to exchange IT capabilities within interactions}

We followed Bharadwaj (2000) taxonomy of IT capabilities to conduct our investigation. This scheme has proven to be advantageous in some respect. Although it was meant to analyse the relationship between IT capabilities and firms' performance (Bharadwaj, 2000), we found the division into IT tangible, human resources and intangible resources particularly useful to assist our research.

Our findings suggested that the acquisition of IT tangible resources in the form of physical infrastructure and software for application development expanded the client's IT capabilities. About the opportunities to exchange IT physical assets in order to create IT capabilities, we obviously consider physical infrastructure and programming software as part of products exchanges within Håkansson's interaction model (Håkansson, 1982). However those tangible resources were combined with human resources skills to create a universal platform of information sharing and distribution, a valuable IT asset from the viewpoint of IT capabilities researchers (Bharadwaj, 1999, 2000; Ross et al., 1996). The combination of IT physical infrastructure with technical skills from users and consultants enhanced the client's opportunity to take advantage of synergies generation between several units. Mata et al. (1995) argued that IT physical assets are easily purchased and duplicated by competitors being unlikely to add value as a source of competitive advantage. We hold a different view and agree with Bharadwaj's (2000) belief that "such a reductionist view of technology, however, seeks to value the infrastructure solely in terms of its individual components, assumes the separability of IT assets, and ignores the synergistic benefits of integrated systems" (p. 172). We back up this view and argue that the combination of IT assets with IT technical skills, which in turn are accessed within interactions between users and consultants, as illustrated by PaintCo-ITSup case especially in the Lotus Notes and ERP episodes, enable the client with opportunities to exploit synergies across business units.

We have already mentioned that in ERP projects knowledge and skills are transferred in a bidirectional flow, from consultants to users and vice versa (Xu and Ma, 2008). Our case corroborated this view, but besides a mere transference of knowledge and skills we argue that is possible to observe a bidirectional flow of IT capabilities. Social exchanges, in the form of informal and intensive relationships between consultants and users, exert a powerful role of leveraging IT capabilities beyond the ones expected to achieve. This is a major finding of this research and led us to a second reflection about the opportunities to exchange IT technical and managerial skills. IT services concerning the physical assets implementation (infrastructure and software) were part of the contracts in different episodes. Consultants and users ought to possess a certain level of technical and managerial skills to implement ITs. In our case, we realized that what was exchanged within the consultancy projects exceeded the contracted product and service package. In one hand and remarkably during ERP episodes, the supplier managed to enhance greatly their human IT resources by training PaintCo's users and ITSup apprentices simultaneously. Service and social exchanges within ERP episodes built a bridge for the supplier to grant technical and managerial skills to their apprentice consultants without additional costs. Furthermore, extended project management capabilities were also highlighted as a major achievement from the supplier. A curious aspect we derived from our analysis is related to the literature on client-consultant relationships where clients are said to seek for structural capital in their relationships with consultants (Willcocks et al., 2004), i.e., the expertise consultancy firms can offer in terms of best practices in the industry. Interestingly, our findings gave us the opposite direction. The supplier claimed vehemently that one of the major outcomes from the episodes with this specific client was the increment of their own capabilities in the best practices for the paint sector which gave them the proper skills to engage self-confidently in new projects in the paint sector. In a second hand, interviewees from the supplier side revealed high appreciation for consultants' availability and patience. This type of social exchanges seems to be the key point to elucidate the process by which PaintCo absorbed technical skills on programming techniques which follows Graubner and Richter's (2003) viewpoint that personal interaction is the major source of relevant knowledge exchange.

From the last two discussion points, we already highlighted the role social interactions may play in enhancing IT intangible capabilities. Hence, about the opportunities to exchange ITenabled intangibles we conclude that IT assets combined with human IT resources encourage the creation of intellectual capital and synergies exploitation that led to a higher customer orientation by providing the tools and information needed to analyse their data, anticipate their needs and provide an active relationship management. This conclusion aligns with Bharadwaj's contributions (Bharadwaj, 2000). Still, it is worthy to emphasize that informal relationships turned out to be a major 
feature of this case and brought out the conditions to exchange ITenabled intangibles.

In sum, we support the viewpoint of the IT capabilities literature (e.g. Bharadwaj, 2000; Mata et al., 1995; Ross et al., 1996; Rockart et al., 1996) that IT capabilities are created or enhanced by the combination of IT resources during day-to-day practice. However, we argue that this creation or enhancement may have the consultancy project as a promising starting point. Consultancy projects observe intense interaction between users and consultants and from this interaction IT capabilities are likely to emerge, to be afterwards refined and improved during daily usage. The perspective held by different fields of research (e.g. IMP work (Mota and de Castro, 2005; Håkansson et al., 1999), capabilities approach (Foss, 1999; Loasby, 1994, 1998)) that relationships work as mechanisms to coordinate resources and capabilities that a company does not possess was illustrated by our case. We extend this vision by arguing that the interaction process is at the heart of such coordination, enhancing IT capabilities exchange, by combining different types of expected exchanges (informations, products, services and especially social exchanges).

\section{Conclusions and limitations}

\subsection{Conclusions and managerial implications}

This article has examined some of the key features of the interaction process within a client-IT supplier relationship whereby IT capabilities may be exchanged and enhanced. The achieved findings and conclusions will be useful not only for the supply side, i.e., IT companies who wish to play an active role as IT capabilities promoters in their customers' IT projects but also for the demand side, especially for IT users and managers responsible for decision-making in IT procurement.

Firstly, this article builds on earlier IMP research that examines the four exchanges types (products and/or services, information, financial and social exchanges) within interaction and has sought to complement this approach with a fifth one of paramount importance: the exchange of IT capabilities in a bidirectional flow mainly achievable within social exchanges. Our study provides strong evidences that throughout client-IT supplier relationships, IT resources from both parties are exchanged and combined enhancing their IT capabilities. This exchange goes beyond the expected (or contracted) exchange of IT physical infrastructure or consultancy services. Rather it also flourishes through the closeness and informality of social relationships between users and consultants. This bilateral access can be explained through the idiosyncrasy of client-consultant relationship featured by daily contacts, informal communication processes and intense knowledge and experience sharing.

Secondly, in line with the previous argument we conclude that social exchanges, outlined from informal and close relationships between consultants and end-users, are important keystones, if not the most important, to allow IT capabilities exchange to occur. Using the interaction model as a valuable approach to investigate the dimensions of a client-IT supplier relationship, we claim that social exchanges perform a crucial role in sustaining and strengthening the relationship. Given that during consultancy projects, IT implementation is featured by frequent, but typical conflicts, close relationships based on mutual trust between consultants and users encouraging cooperation and conflict resolution and tend to reduce uncertainty during IT projects.

The PaintCo-ITSup case also exemplified how companies may expand or enhance their capabilities portfolio through social interaction with an IT supplier/consultant, whether they are involved or not in consultancy projects. It was highlighted that given the peculiarity of intermittent transactions, social exchange is imperative to fill in the discontinuity between IT projects. Therefore, we acknowledge that in high-technology products/ services markets, and not only in the IT context, the frequency of buyer-supplier transactions is low since companies engage in this type of investments in a rather irregular basis. In this sense, during these discontinuity periods, social bonds between actors may be lost and the opportunity to enhance IT capabilities may fade away. It is vital to keep social contact and engage in activities (seminars, fairs and new product presentations) to reduce the formality of the relationship as demonstrated by our case study.

Fourthly, the paper draws attention to the fact that managing a capabilities gap, between existent and necessary capabilities, is a problem faced by all companies whether they are searching for IT capabilities or other types of capabilities. In this sense, companies have to evaluate their options and take "make or buy" decisions to overcome this gap. They can manage the gap exogenously through access to third parties relying on IT suppliers or consultants or endogenously through internal development of the non-existent capabilities. The exogenous route requires necessarily the construction and management of relationships with third parties. As demonstrated by our case, the process to expand a firm's IT capabilities within client-IT relationships is long, complex and painful, especially when a large number of changes and adaptations arise. This is due to gaps between the buyer's capability to choose the product/service they need and the supplier's ability to meet their customers' needs. This is particularly relevant in the IT market where customers not always know what to buy. In this case, companies may be keen to look for more players (for example external consultants or advisors) to minimize their capabilities gap. In our case, for example, attention was focused on a dyadic relationship but it was known that PaintCo normally takes advice from an external consultant to evaluate their decisions on IT procurement. The endogenous route, in turn, requires an internal organisation of in-house capabilities. Consultancy projects are long but not endless. IT managers and users, like someone who is learning how to drive, must be willing to practice, fail, retry and improve. Thus "learning by doing" processes are also a vehicle to boost the firm's IT capabilities. Moreover, companies, who were engaged in consultancy projects in the past, may be willing to engage in new IT projects and expand their IT capabilities without external help. They may combine the technical and managerial skills obtained by learning from previous projects with the new physical IT infrastructure and achieve new capabilities that were previously absent.

In sum, we conclude that managers, IT users, consultants and IT suppliers may increase their understanding of how interactions may facilitate IT capabilities exchange across their buyer-supplier relationships and how social interactions, whether developed within, between or after consultancy projects, may arise as a promising starting point to create or enhance IT capabilities. In fact, we claim that social exchanges, in the form of informal and intensive relationships between people from both companies, exert a powerful role of leveraging IT capabilities beyond the ones expected to achieve. In this sense, given the current state of the consultancy market where capabilities, commitment and even reputation are being cautiously tested by existing and potential clients, our findings may possibly help software houses and consultancy firms reflecting on the role they wish to play as IT suppliers_an active role as a skilful partner capable of enhancing their clients' IT capabilities or a passive role as a mere IT implementer. IT buyers, in turn, may get the most of their relationships with IT suppliers by engaging their staff in proactive "learning by doing" practices towards the enhancement of IT capabilities, within or beyond consultancy projects. 


\subsection{Limitations and suggestions for future research}

This paper seeks to provide new insights on the understanding of a specific business relationship rather than to generalize findings. By adopting a single-case study design with embedded sub-cases we intended to carry out an in-depth analysis of the relevant dimensions of a client-IT supplier relationship whose findings cannot be universally extended to similar dyads. In this sense, the comprehensive analysis of eighteen episodes of interaction uncovered a new perspective on the type of exchanges observed in a buyer-IT supplier relationship, particularly the consideration of IT capabilities as a key exchange. In view of that, we suggest that future research could take this case study as a constructive point of departure to expand the analysis to other cases of buyer-IT suppliers. By integrating a multiple-case study design, research may lead to more robust conclusions that can then be generalized to relationships of similar nature.

A limitation that can be pointed out is that the research draws solely on the analysis of a dyad. The vast network in which the dyad is embedded was not considered. According to the IMP work (Axelsson and Easton, 1992; Håkansson and Johanson, 1992), companies are believed to be embedded in a network of interconnected relationships. Therefore, the outcomes of a company's decisions and actions will always be affected and affect other companies' activities. These aspects were not considered in this research. Again, this may be considered as an opportunity for future research by looking at the client-IT supplier relationship in a network research context.

Finally, it should be highlighted that little research can be found on client-IT supplier relationship and consultancy-based relations adopting the IMP framework. Relationships centred on client-IT suppliers, IT outsourcing and IT-based consultancy are receiving increasing attention from managers and researchers due to its strong adherence and importance to current managerial reality. This paper along with a few others (Kern and Willcocks, 2002; Leek et al., 2003; Naudé et al., 2000) have proven the relevance of the interaction approach as an insightful tool to investigate business relationships of this nature. Moreover further research would allow a better understanding of the exchange process as a driver to enhance IT capabilities. Other studies centred on a different set of capabilities would also be vital to examine the inclusion of this fifth element in the exchange process of the interaction approach.

\section{Acknowledgements}

We would like to thank Professor Luis Araujo for his valuable feedback on previous drafts of this paper. We would also like to thank anonymous reviewers for their thoughtful comments.

Table A1

Relationship episodes.

\begin{tabular}{|c|c|c|c|}
\hline \# & Period & Episode & Main features \\
\hline 1 & 1980-1990 & $\begin{array}{l}\text { Engagement in a partnership to develop a } \\
\text { solution suitable to the painting industry. }\end{array}$ & $\begin{array}{l}\text { Staff from customer's IT department and staff from the IT supplier jointly developed and } \\
\text { tested a software solution to be used in accounting and finance area. }\end{array}$ \\
\hline 2 & 1999 & $\begin{array}{l}\text { PaintCo purchases the electronic e-mail solution } \\
\text { from ITSup. }\end{array}$ & $\begin{array}{l}\text { The customer decides to substitute their exchange e-mail platform by ITSup's Lotus Notes } \\
\text { notes solution (Domino platform). }\end{array}$ \\
\hline 3 & 2000 & $\begin{array}{l}\text { PaintCo purchases IT and services within a } \\
\text { consultancy project to implement workflow } \\
\text { solutions. }\end{array}$ & $\begin{array}{l}\text { From the previous episode where PaintCo starts to work with Domino platform, it was } \\
\text { possible to develop several internal workflow solutions (price maintenance, colour } \\
\text { maintenance, products in stock maintenance based on that technology). }\end{array}$ \\
\hline 4 & & $\begin{array}{l}\text { PaintCo demands the supplier for a } \\
\text { demonstration of a CRM solution suitable to their } \\
\text { sector. }\end{array}$ & $\begin{array}{l}\text { The supplier prepares a demonstration of the CRM software after having several meetings } \\
\text { to better understand the context of painting sector. The client ends up buying a solution } \\
\text { from an ITSup competitor. }\end{array}$ \\
\hline 5 & & $\begin{array}{l}\text { PaintCo demands the supplier for a } \\
\text { demonstration of an ERP solution suitable to } \\
\text { their sector. }\end{array}$ & $\begin{array}{l}\text { PaintCo decides to search for an ERP solution capable of unifying the information systems } \\
\text { of all the companies of the group. ITSUP is shortlisted as a potential supplier. }\end{array}$ \\
\hline 6 & 2001 & $\begin{array}{l}\text { ITSup is selected as ERP supplier which involved } \\
\text { a first phase of needs evaluation among the } \\
\text { client's departments. }\end{array}$ & $\begin{array}{l}\text { To pre-prepare the implementation of the ERP solution in Portugal and Spain, an intensive } \\
\text { period of meetings and discussion groups with ITSup, PaintCo and IBM as external adviser } \\
\text { were arranged to identify what issues should be addressed by the software. }\end{array}$ \\
\hline 7 & & $\begin{array}{l}\text { Start-up: implementation of ERP project starts in } \\
\text { PaintCo's headquarters } \\
\text { ERP phase } 1\end{array}$ & $\begin{array}{l}\text { Start-up of the project with an action plan divided in } 3 \text { stages: i) implementation in } \\
\text { financial (FIN) area, simultaneously in Portugal and Spain; ii) implementation of supply } \\
\text { chain management (SCM) area in Portugal; iii) implementation of supply chain } \\
\text { management (SCM) area in Spain; }\end{array}$ \\
\hline 8 & & $\begin{array}{l}\text { ERP phase 1: during the first stage of FIN's } \\
\text { implementation a number of adaptations to } \\
\text { software were identified and developed in order } \\
\text { to suit the painting sector. }\end{array}$ & $\begin{array}{l}\text { In the process of implementing and training final users, a number of non-conformities } \\
\text { were identified. PaintCo's users demanded for adaptations in FIN software in order to fill } \\
\text { their needs. This involved the arrangement of numerous and frequent meetings to re- } \\
\text { design a new FIN prototype and a long period of software development to correct non- } \\
\text { conformities. }\end{array}$ \\
\hline 9 & 2002 & $\begin{array}{l}\text { ERP phase 1: real start-up of finance area in } \\
\text { Portugal and Spain }\end{array}$ & $\begin{array}{l}\text { The FIN area "goes live" in January 2002, simultaneously in Portugal and Spain. Period of } \\
\text { high tension but without severe problems. }\end{array}$ \\
\hline 10 & & $\begin{array}{l}\text { ERP phase 2: implementation of ERP project } \\
\text { continues with the SCM area in PaintCo's } \\
\text { headquarters }\end{array}$ & $\begin{array}{l}\text { Key users from procurement, production, logistics, distribution, procurement, sales and } \\
\text { marketing are involved with consultants to design a SCM prototype. }\end{array}$ \\
\hline 11 & & $\begin{array}{l}\text { ERP phase } 2 \text { : during the implementation and } \\
\text { training of SCM final users, an outstanding } \\
\text { number of adaptations to software were } \\
\text { identified }\end{array}$ & $\begin{array}{l}\text { Again SCM area detected a huge amount of non-conformities to software in order to suit } \\
\text { the painting sectors which led to a new phase only dedicated to discuss those adaptations } \\
\text { and re-design the prototype. }\end{array}$ \\
\hline 12 & 2003 & $\begin{array}{l}\text { ERP phase 2: analysis of requested adaptations, } \\
\text { decision-making on which adaptations should be } \\
\text { developed. }\end{array}$ & $\begin{array}{l}\text { Given the massive number of adaptations requested by SCM final users, a long period of } \\
\text { meetings and discussion groups with ITSup and PaintCo were arranged to structure a cost- } \\
\text { analysis plan and identify what non-conformities should be address and what adaptations } \\
\text { should be developed. }\end{array}$ \\
\hline 13 & & $\begin{array}{l}\text { A new presentation of the supplier's CRM } \\
\text { software is demanded by PaintCo. }\end{array}$ & $\begin{array}{l}\text { Once again PaintCo expresses an interest in ITSup's CRM solution since the one } \\
\text { implemented in } 2000 \text { was abandoned by PAINTCO's users. Since the relationship evolved } \\
\text { in a close partnership in last } 3 \text { years, ITSup is selected as supplier of CRM solution and } \\
\text { implementation. }\end{array}$ \\
\hline
\end{tabular}


Table A1 (continued)

\begin{tabular}{|c|c|c|c|}
\hline \# & Period & Episode & Main features \\
\hline 14 & 2004 & $\begin{array}{l}\text { CRM phase I: implementation of CRM project in } \\
\text { PaintCo's headquarters }\end{array}$ & $\begin{array}{l}\text { As PaintCo is implementing ITSup's ERP solution, the interfaces between ERP and PaintCo's } \\
\text { solutions are totally compatible, and easily implemented. }\end{array}$ \\
\hline 15 & & $\begin{array}{l}\text { ERP phase 2: real start-up of SCM area in } \\
\text { Portugal }\end{array}$ & $\begin{array}{l}\text { The SCM area "goes live" in Portugal in December } 2004 \text { after } 2 \text { years of needs evaluation, } \\
\text { non-conformities corrections, and adaptations to software. }\end{array}$ \\
\hline 16 & 2005 & CRM phase II: “CRM dynamization project” & $\begin{array}{l}\text { PaintCo realized that for a second time users were not using CRM tools. They decided to } \\
\text { find out the reasons behind the non-adherence and motivate the use of CRM ITs. A new } \\
\text { project was developed with the presence of an ITSup consultant working with end-users } \\
\text { in a daily-basis during } 2 \text { months. }\end{array}$ \\
\hline 17 & 2006 & ERP phase 2: real start-up of SCM area in Spain & The SCM area "goes live" in Spain during 2006 \\
\hline \multirow[t]{2}{*}{18} & 2006 & CRM phase III: “CRM mobility project” & $\begin{array}{l}\text { A new project is planned after the } 2005 \text { Dynamization project. PaintCo wants to grant } \\
\text { their commercial staff with CRM tools in PDAs (personal digital assistant). }\end{array}$ \\
\hline & $\begin{array}{l}\text { Draft } \\
\text { schedule }\end{array}$ & $\begin{array}{l}\text { CRM Phase I: implementation of CRM project in } \\
\text { Spain }\end{array}$ & The CRM area is planned to "go live" in Spain during 2006. \\
\hline
\end{tabular}

\section{Appendix A}

\section{See Table A1.}

\section{References}

Axelsson, B., Easton, G. (Eds.), 1992. Industrial Networks: A New View of Reality. Routledge, London.

Barney, J., 1991. Firm resources and sustained competitive advantage. Journal of Management 17 (1), 99.

Bharadwaj, A.S., 2000. A resource-based perspective on information technology capability and firm performance: an empirical investigation. MIS Quarterly 24 (1), 169.

Bharadwaj, A.S., Sambamurthy, V., Zmud, R.W., 1999. IT capabilities: theoretical perspectives and empirical operationalization. In: Proceedings of the 20th International Conference on Information Systems. Association for Information Systems, Charlotte, NC, USA.

Bonoma, T.V., 1985. Case research in marketing: opportunities, problems, and a process. JMR, Journal of Marketing Research 22 (2), 199.

Chornoboy, K., Gardner, H.W., 1990. Client/consultant relations. ARMA Records Management Quarterly 24 (2), 28.

Clemons, E.K., Row, M.C., 1991. Sustaining IT advantage: the role of structural differences. MIS Quarterly 15 (3), 275.

Cova, B., Salle, R., 2000. Rituals in managing extrabusiness relationships in international project marketing: a conceptual framework. International Business Review 9 (6), 669.

Dawes, P.L., Lee, D.Y., Midgley, D., 2007. Organizational learning in high-technology purchase situations: the antecedents and consequences of the participation of external IT consultants. Industrial Marketing Management 36 (3), 285.

Dubois, A., Gadde, L.E., 2002. Systematic combining: an abductive approach to case research. Journal of Business Research 55 (7), 553-560.

Dubois, A., Araujo, L., 2004. Research methods in industrial marketing studies. In: Håkansson, H., Harrison, D., Waluszewski, A. (Eds.), Rethinking Marketing. Developing a New Understanding of Markets. Wiley, Chichester, pp. 207-228.

Dubois, A., Araujo, L., 2007. Case research in purchasing and supply management: opportunities and challenges. Journal of Purchasing and Supply Management 13 (3), 170.

Duhan, S., 2007. A capabilities based toolkit for strategic information systems planning in SMEs. International Journal of Information Management 27 (5), 352 .

Easton, G., 1998. Case research as a methodology for industrial networks: a realist apologia. In: Naude, P., Turnbull, P. (Eds.), Network Dynamics in International Marketing. Pergamon, Oxford, pp. 73-87.

Feeny, D.F., Willcocks, L.P., 1998. Core IS capabilities for exploiting information technology. Sloan Management Review 39 (3), 9.

Flowers, S., 2007. Organizational capabilities and technology acquisition: why firms know less than they buy. Industrial Corporate Change 16 (3), 317-346.

Ford, D., 1980. The development of buyer-seller relationships in industrial markets. European Journal of Marketing 14 (5/6), 339-354.

Ford, D. (Ed.), 2002. Understanding Business Marketing and Purchasing, third ed. Thomson Learning, London.

Ford, D., Johanson, J., Håkansson, H., 1986. How do companies interact? Industrial Marketing and Purchasing 1 (1), 25-41.

Ford, D., et al., 1998. Managing Business Relationships. Wiley, Chichester.

Ford, D., et al., 2003. Managing business relationships. In: Edition, S. (Ed.). Wiley, Chichester.

Foss, N.J., 1999. Networks, capabilities and competitive advantage. Scandinavian Journal of Management 15 (1), 1-15

Foss, N.J., Loasby, B.J. (Eds.), 1998. Economic Organization, Capabilities and Coordination. Essays in Honour of G.B. Richardson, vol. 8. Routledge Studies in Business Organization and Networks, Routledge, London.
Foss, N.J., Roberston, P.L. (Eds.), 2000. Resources, Technology and Strategy Explorations in the Resource-based Perspective. Routledge Advances in Management and Business Studies, Routledge, London.

Gonzalez, R., Gasco, J., Llopis, J., 2006. Information systems outsourcing: a literature analysis. Information \& Management 43 (7), 821.

Goo, J., et al., 2007. An investigation of factors that influence the duration of IT outsourcing relationships. Decision Support Systems 42 (4), 2107.

Graubner, M., Richter, A., 2003. Managing tomorrow's consulting firm. Consulting to Management-C2M 14 (3), 43.

Håkansson, H. (Ed.), 1982. International Marketing and Purchasing of Industrial Goods: An Interaction Approach. Wiley, Chichester.

Håkansson, H. (Ed.), 1987. Industrial Technological Development: A Network Approach. Croom-Helm, London.

Håkansson, H., Ford, D., 2002. How should companies interact in business networks? Journal of Business Research 55 (2), 133-139.

Håkansson, H., Johanson, J., 1992. A Model of Industrial Networks, in Industrial Networks: A New View of Reality. In: Axelsson, B., Easton, G. (Eds.). Routledge, London, pp. 28-38.

Håkansson, H., Prenkert, F., 2004. Exploring the exchange concept in marketing In: Håkansson, H., Harrison, D., Waluszewski, A. (Eds.), Rethinking Marketing. Developing a New Understanding of Markets. Wiley, Chichester, pp. 75-94.

Håkansson, H., Snehota, I., 1989. No business is an Island: the network concept of business strategy. Scandinavian Journal of Management 4 (3), 187-200.

Håkansson, H., Snehota, I. (Eds.), 1995. Developing Relationships in Business Networks. Routledge, London.

Håkansson, H., Havila, V., Pedersen, A.C., 1999. Learning in networks. Industrial Marketing Management 28 (5), 443-452.

Hurley, M., 2001. IT outsourcing-managing the key asset. Information Management \& Computer Security 9 (5), 243.

Johnston, W.J., Leach, M.P., Liu, A.H., 1999. Theory testing using case studies in business-to-business research. Industrial Marketing Management 28 (3), 201.

Karantinou, K.M., Hogg, M.K., 2001. Exploring relationship management in professional services: a study of management consultancy. Journal of Marketing Management 17 (3/4), 263.

Kern, T., Willcocks, L., 2002. Exploring relationships in information technology outsourcing: the interaction approach. European Journal of Information Systems 11 (1), 3.

Kishore, R., et al., 2003. A relationship perspective on IT outsourcing. Communications of the ACM 46 (12), 86.

Lacity, M.C., Willcocks, L.P., Feeny, D.F., 1996. The value of selective IT sourcing Sloan Management Review 37 (3), 13.

Lai, V.S., Mahapatra, R.K., 1997. Exploring the research in information technology implementation. Information \& Management 32 (4), 187.

Larwood, L., Gattiker, U.E., 1986. Client and consultant management problemsolving values. Group \& Organization Studies 11 (4), 374.

Leek, S., Turnbull, P.W., Naudé, P., 2003. How is information technology affecting business relationships? Results from a UK survey. Industrial Marketing Management 32 (2), 119

Loasby, B.J., 1994. Organisational capabilities and interfirm relations. Metroeconomica 45 (3), 248-265.

Loasby, B.J., 1998. The organisation of capabilities. Journal of Economic Behavior \& Organization 35 (2), 139-160.

Lui, K.M., Chan, K.C.C., 2008. Rescuing troubled software projects by team transformation: a case study with an ERP Project. IEEE Transactions on Engineering Management 55 (1), 171.

Mata, F.J., Fuerst, W.L., Barney, J.B., 1995. Information technology and sustained competitive advantage: a resource-based analysis. MIS Quarterly 19 (4), 487.

Mike, T., 2003. What clients want in consultants. Design Management Journal 14 (3), 10

Mota, J., de Castro, L.M., 2005. Relationship portfolios and capability development: cases from the moulds industry. Journal of Purchasing and Supply Management 11 (1), 42. 
Mulligan, P., 2002. Specification of a capability-based IT classification framework Information \& Management 39 (8), 647.

Naudé, P., Turnbull, P.W., Leek, S., 2000. Is the interaction approach of any relevance in an IT/e-commerce. In: Proceedings of the16th Industrial Marketing and Purchasing Conference. Bath, UK.

Niewiem, S., Richter, A., 2004. The changing balance of power in the consulting market. Business Strategy Review 15 (1), 8.

Powell, T.C., Dent-Micallef, A., 1997. Information technology as competitive advantage: the role of human, business, and technology resources. Strategic Management Journal 18 (5), 375-405.

Rockart, J.F., Earl, M.J., Ross, J.W., 1996. Eight imperatives for the new IT organization. Sloan Management Review 38 (1), 43.

Ross, J.W., Beath, C.M., Goodhue, D.L., 1996. Develop long-term competitiveness through IT assets. Sloan Management Review 38 (1), 31.

Shah, Y., 1990. Understanding client-consultant interaction. Cost Engineering 32 (6), 9
Tippins, M.J., Sohi, R.S., 2003. IT competency and firm performance: is organizational learning a missing link? Strategic Management Journal 24 (8), 745-761.

Webster, J., 1995. Networks of collaboration or conflict? Electronic data interchange and power in the supply chain. The Journal of Strategic Information Systems 4 (1), 31.

Willcocks, L., et al., 2004. IT and business process outsourcing: the knowledge potential. Information Systems Management 21 (3), 7.

$\mathrm{Xu}, \mathrm{Q} ., \mathrm{Ma}, \mathrm{Q} ., 2008$. Determinants of ERP implementation knowledge transfer. Information \& Management 45 (8), 528.

Yin, R.K., 1994. Case Study Research: Design and Methods, second ed. Sage, Newbury Park, CA.

Yongbeom, K., Jeffrey, H., Mel, S., 2006. An update on the IS/IT skills gap. Journal of Information Systems Education 17 (4), 395.

Zimmerman, J.G., Zelnio, R.N., 1986. Toward better client-consultant relationships. Medical Marketing and Media 21 (4), 32. 